\title{
Giant Cell Arteritis of the Breast
}

\author{
J.T. Anima E.J. van Herk ${ }^{b}$ \\ a Department of Pathology, Faculty of Medicine, Kuwait University, b Department of Surgery, Al-Hadi Clinic, Kuwait
}

\author{
Key Words \\ Breast · Giant cell arteritis · Mastectomy
}

\begin{abstract}
Objective: To report a rare case of giant cell arteritis of the breast in a 56-year-old woman. Clinical Presentation and Intervention: The patient presented with tenderness in the upper outer quadrant of the left breast, in the absence of any constitutional symptoms. A diagnosis of giant cell arteritis was made only after surgical wedge excision of the affected breast quadrant. She returned 6 weeks later with tenderness in the upper inner medial quadrant of the same breast, with a raised erythrocyte sedimentation rate. She has since been referred to the rheumatologist for further management. Conclusion: The diagnosis of giant cell arteritis of the breast was made only after pathological examination of the excised breast tissue. This study focused attention on the need to be aware of systemic conditions that may present as localised lesions of the breast and to maintain a high index of clinical suspicion in order to adequately investigate them and perhaps avoid unnecessary radical surgical intervention such as mastectomy.
\end{abstract}

Copyright (C) 2004 S. Karger AG, Basel

\section{Introduction}

Primary involvement of giant cell arteritis in the breast is a rare occurrence. It is more likely to involve the breast as part of a systemic vascular disease. Mammary arteritis was first reported by Waugh in 1950 [1] and subsequently as single case reports in the literature. To date, there are less than 20 case reports of mammary giant cell arteritis, either as the presenting feature, or as a dominant feature in the presentation of a more generalised disease [2-6]. The disorder occurs mainly in older women, over 55 years of age and when the breast is the only organ affected, and the patient presents with a breast mass, the condition may mimic carcinoma and even lead to mastectomy [7, 8]. Thus, the condition has presented as a fixed or mobile lump, or as a tender or non-tender indurated area in the breast. Some authors consider giant cell arteritis of the breast as a unique syndrome, since the majority of reported cases show no systemic involvement [7]. We present the case of a 56-year-old woman with localised tenderness in her breast, biopsy of which revealed the typical morphological features of giant cell arteritis.

\section{Case Report}

A 56-year-old woman presented to a private hospital with a 2 week history of tenderness in her left breast, with no associated fever or nipple discharge. She was a multipara 4 and 5 years after menopause, with no family history of breast cancer or other relevant personal history. Examination confirmed localised tenderness in the upper outer quadrant, with no definite mass in the left breast, or palpable axillary lymph nodes. She did not have fever. Mammography and ultrasound showed no definite masses or changes to suggest malignancy, but there was infiltration in the upper outer quadrants of both breasts, which by ultrasound suggested dense glandular tissue. She was reassured and sent home without treatment, but returned 2 weeks later, concerned about the possibility of cancer and requested surgery. Her laboratory, haematological and biochemical profiles revealed no abnormality. Erythrocyte sedimentation rate (ESR) was not requested at this time. Chest X-ray was also normal. A wedge excision of her left breast upper outer quadrant was carried out and the tissue sent for histopathological examination. Postoperatively, the wound healed without complications. Six weeks postoperatively,

\section{KARGER \\ Fax + 41613061234 \\ E-Mail karger@karger.ch}

www. karger.com (c) 2004 S. Karger AG, Basel

1011-7571/04/0134-0234\$21.00/0

Accessible online at:

www. karger.com/mpp
Dr. J.T. Anim

Department of Pathology, Faculty of Medicine

Kuwait University, PO Box 24923

13110 Safat (Kuwait) 
Fig. 1. Transmural inflammation of the arterial wall, showing organizing thrombus filling the lumen $(\mathrm{T})$ and a giant cell in the inflammatory infiltrate (arrow). HE. $\times 400$.
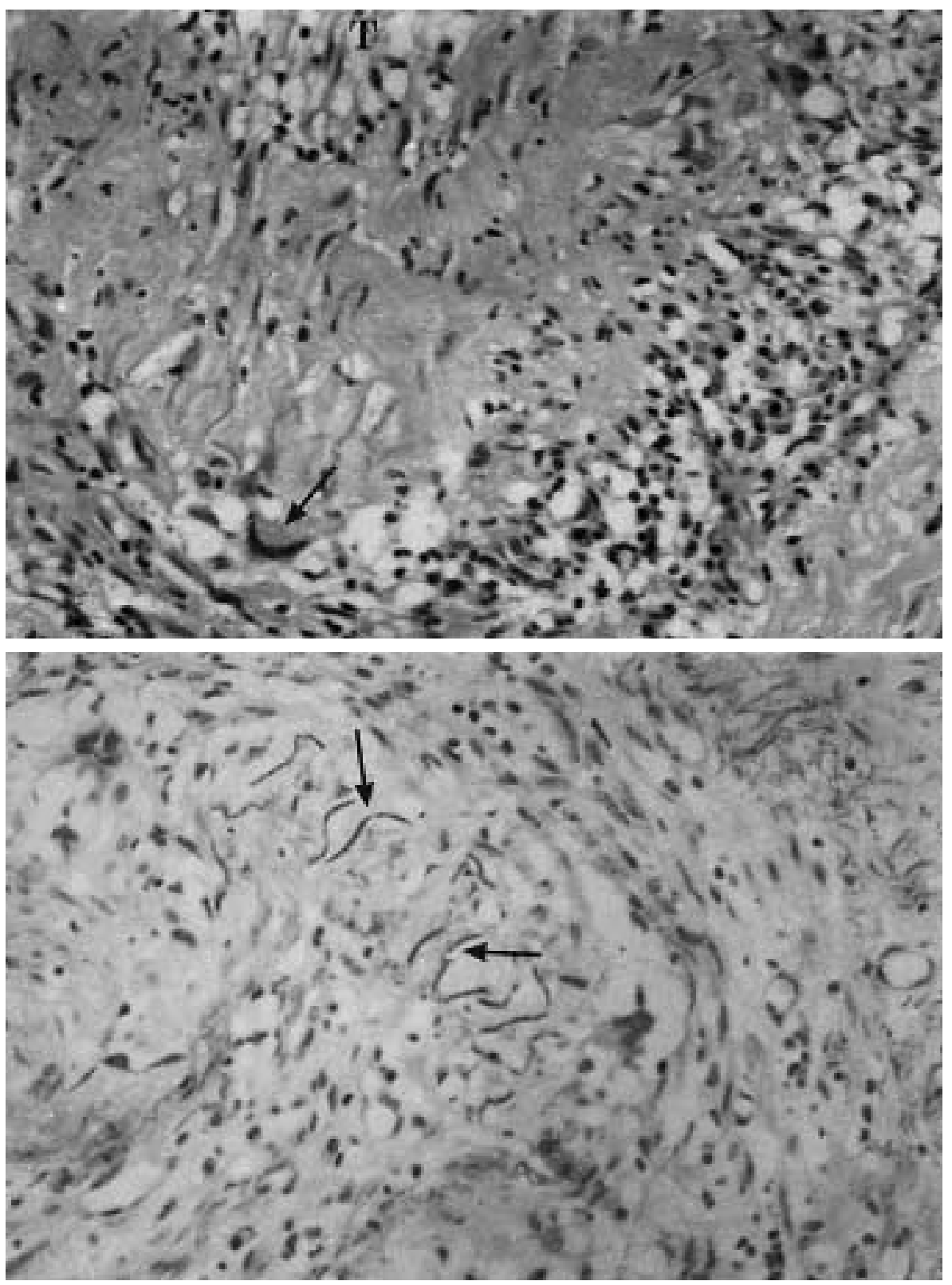

Fig. 2. Fragmented internal elastic lamina in the arterial wall (arrows). Elastic van Gieson stain. $\times 400$.

at follow-up, a slight induration of the medial aspect of the same breast was detected. Blood examination at this time showed elevated ESR of $67 \mathrm{~mm} / \mathrm{h}$. She was referred to the rheumatologist for further evaluation and management.

\section{Pathological Findings}

The specimen consisted of a soft fibro-fatty tissue $(3.5 \times 3.0 \times$ $1.5 \mathrm{~cm})$. Serial sections showed dark-brown areas but no definite masses. Microscopy showed transmural inflammation of mediumsized to small arteries with occlusion of their lumina by organizing thrombi (fig. 1). There was fragmentation of internal elastic lamina as demonstrated by elastic van Gieson stain (fig. 2), with giant cell reaction within the vessel wall. Veins showed no significant abnormality, and the surrounding breast showed stromal fibrosis and mild focal chronic inflammation. There was no malignancy. The above histological features were consistent with giant cell arteritis of the breast.

\section{Discussion}

Our patient presented with localised tenderness in the breast, with no palpable mass or imaging evidence of a lesion suggesting malignancy. In the circumstances, the wedge excision, unnecessary as it turned out to be later, was useful in establishing the diagnosis, while also assuag- 
ing the patient's anxiety. It is also recognised that tissue biopsy provides the key to diagnosis in most cases [2], while also serving to exclude the presence of cancer.

Other forms of arteritis have been reported to involve the breast. These include polyarteritis nodosa [9-11], Wegener's granulomatosis [12, 13], and the breast may be a rare site for apparently localised vasculitis in these conditions. In younger subjects, disparate clinical diagnoses including puerperal mastitis [8], spontaneous infarction of breast tissue during pregnancy or lactation, Mondor's disease [7] or even inflammatory breast carcinoma [3] have been made. In case of systemic manifestations, such as anorexia, weight loss, lethargy and arthralgia (symptoms suggestive of polymyalgia rheumatica), these may be pointers to the correct diagnosis [6]. In some cases, the breast presentation has been concurrent with manifestations of temporal arteritis, with classical histological findings on temporal artery biopsy [5]. Several authors have reviewed the clinical and laboratory findings of cases reported in the literature in order to enhance the general understanding of the disorder [1, 3, 4, 7] and to provide a clearer definition of giant cell arteritis of the breast.

In our patient, the diagnosis became apparent only after histopathological examination of the excised breast tissue. It is worth pointing out that fine needle aspiration cytology was not done in the patient because the private hospital where she was admitted does not have cytopathology facilities. Even then, fine needle aspiration cytology is likely to help in demonstrating an inflammatory process but unlikely to yield a definitive diagnosis. This area, obviously, requires more study, as many more cases are encountered. The prominence of breast tissue in both upper outer quadrants as shown on ultrasound may suggest that both breasts may have been involved at the time of presentation, but the right breast to a lesser degree. An
ESR at the time of initial presentation might have helped, although this is often a non-specific finding. It is worthy of note that in the perimenopausal period, most constitutional symptoms are confused with menopausal changes and may not be given due attention in the investigation of constitutional symptoms associated with giant cell arteritis. Moreover, because lesions of giant cell arteritis of the breast may be non-tender or present in breasts with fibrocystic changes, they may go unrecognised. All these may contribute to under-diagnosis and under-reporting of the condition. Establishment of the diagnosis, however, does not preclude the presence of coexistent breast cancer as previously reported $[1,4]$. This emphasises the importance of biopsy in the diagnosis of this condition.

This case brings into focus the need to be aware of the systemic conditions which may present as localised lesions of the breast and to maintain a high index of clinical suspicion in order to adequately investigate them and also to avoid unnecessary radical surgical interventions, such as mastectomy, that have been carried out in the past. Once the diagnosis has been made, the outcome is said to be favourable, with prompt clinical response to steroid treatment and no reported mortality. Indeed, some patients have required no treatment and had a self-limited clinical course, thus justifying the suggestion by some authors [7] that giant cell arteritis of the breast be regarded as a unique syndrome.

\section{Conclusion}

The diagnosis of giant cell arteritis of the breast was made only after pathological examination of the excised breast tissue.

\section{References}

1 McKendry RJR, Guindi M, Hill DP: Giant cell arteritis (temporal arteritis) affecting the breast: Report of two cases and review of published reports. Ann Rheum Dis 1990;49:10011004.

2 Lau Y, Mak YF, Hui PK, Ahchong AK: Giant cell arteritis of the breast. Aust NZ J Surg 1996; 66:259-261.

3 Cook DJ, Bensen WG, Carroll JJ, Joshi S: Giant cell arteritis of the breast. CMAJ 1988; 139:513-515.

4 Clement PB, Senges H, How AR: Giant cell arteritis of the breast: Case report and literature review. Hum Pathol 1987;18:1186-1189.
5 Chaitin B, Kohout ND, Goldman RL: Focal arteritis of the breast. Angiology 1981;32:334337.

6 Dega FJ, Hunder GG: Vasculitis of the breast. Arthritis Rheum 1974;17:973-976.

7 Susmano A, Roseman D, Haber MH: Giant cell arteritis of the breast: A unique syndrome. Arch Intern Med 1990;150:900-904.

8 Potter BT, Housley E, Thomson D: Giant cell arteritis mimicking carcinoma of the breast. $\mathrm{Br}$ Med J 1981;282:1665-1666.

9 Trueb RM, Scheidegger EP, Pericin M, Singh A, Hoffmann U, Sauvant G, Burg G: Periarteritis nodosa presenting as a breast lesion: Report of a case and review of the literature. Br J Dermatol 1999;141:1117-1121.
10 Pappo I, Beglaibter N, Amir G: Mammary arteritis mimicking cancer. Eur J Surg 1992; 158:191-193.

$11 \mathrm{Ng}$ WF, Chow LTC, Lam PWY: Localized polyarteritis nodosa of breast - Report of two cases and review of the literature. Histopathology 1993;23:535-539.

12 Deininger HK: Wegener granulomatosis of the breast. Radiology 1985;154:59-60.

13 Jordan JM, Rowe WT, Allen NB: Wegener's granulomatosis involving the breast. Am J Med 1987;83:159-164. 